University of New Hampshire

University of New Hampshire Scholars' Repository

Faculty Publications

$1-4-2019$

\title{
Actions speak louder than words: designing transdisciplinary approaches to enact solutions
}

\author{
Vanessa R. Levesque \\ University of New Hampshire, Durham, Vanessa.Levesque@unh.edu \\ Aram J. K. Calhoun \\ University of Maine, Orono \\ Kathleen P. Bell \\ University of Maine, Orono
}

Follow this and additional works at: https://scholars.unh.edu/faculty_pubs

\section{Comments}

This is an Accepted Manuscript. The final publication is available at Springer via https://dx.doi.org/10.1007/

s13412-018-0535-0

\section{Recommended Citation}

Levesque, V.R., Bell, K.P., Calhoun, A.J.K. 2019. Actions speak louder than words: Designing transdisciplinary approaches to enact solutions. Journal of Environmental Studies and Sciences.

This Article is brought to you for free and open access by University of New Hampshire Scholars' Repository. It has been accepted for inclusion in Faculty Publications by an authorized administrator of University of New Hampshire Scholars' Repository. For more information, please contact Scholarly.Communication@unh.edu. 


\title{
Actions speak louder than words: Designing transdisciplinary approaches to enact solutions
}

\author{
Abstract \\ Sustainability science uses a transdisciplinary research process in which academic and non- \\ academic partners collaborate to identify a common problem and co-produce knowledge to develop \\ more sustainable solutions. Sustainability scientists have advanced the theory and practice of facilitating \\ collaborative efforts such that the knowledge created is usable. There has been less emphasis, however, \\ on the last step of the transdisciplinary process: enacting solutions. We analyzed a case study of a \\ transdisciplinary research effort in which co-produced policy simulation information shaped the creation \\ of a new policy mechanism. More specifically, by studying the development of a mechanism for \\ conserving vernal pool ecosystems we found that four factors helped overcome common challenges to \\ acting upon new information: creating a culture of learning, co-producing policy simulations that acted \\ as boundary objects, integrating research into solution development, and employing an adaptive \\ management approach. With an increased focus on these four factors that enable action, we can better \\ develop the same level of nuanced theoretical concepts currently characterizing the earlier phases of \\ transdisciplinary research, and the practical advice for deliberately designing these efforts.
}

Key words: collaboration, co-production, transdisciplinary, knowledge to action, land use policy, vernal pool 


\section{Introduction}

A key goal of sustainability science is to develop creative, equitable and socially relevant solutions to complex, 'wicked' problems (Brandt et al., 2013; Clark, 2007; Clark \& Dickson, 2003; McKee, Guimaraes, \& Pinto-Correia, 2015; Miller, 2013; Polk, 2014; Wiek et al., 2015). Yet sustainability researchers are increasingly aware of the difficultly in doing so, and are interested in ensuring that their work produces knowledge that spurs action addressing the complex problems on which they focus (Clark, van Kerkhoff, Lebel, \& Gallopin, 2016). In many settings, effective work towards solutions requires researchers from multiple disciplines to collaborate with non-academic partners who can contribute context-specific and practice-based knowledge (Jacobs et al., 2016), and for these collaborative teams to integrate and apply the new knowledge (Binder, Absenger-Helmli, \& Schilling, 2015; Zscheischler \& Rogga, 2015). A transdisciplinary research framework offers an attractive approach because it ideally includes the integration of multiple disciplines along with the expertise of nonacademic partners in the co-production of solutions-oriented and socially relevant knowledge (Binder et al., 2015; Polk, 2015). We define co-production as these interactions between researchers and nonacademic actors to produce and apply policy-relevant science (van Kerkhoff \& Lebel, 2015; Wyborn, 2015).

While transdisciplinary research can potentially enable researchers to contribute to societal challenges and help local stakeholders tap into expertise, it also takes time and effort from both stakeholders and researchers and there is not yet certainty that such an effort will result in improved outcomes (Godemann, 2008; Miller et al., 2014; Polk, 2014; Wiek et al., 2015). Although there have been some prominent examples of successfully linking knowledge to action (Buizer, Jacobs, \& Cash, 2016; Clark, Tomich, et al., 2016; Clark, van Kerkhoff, et al., 2016; Hart \& Calhoun, 2010; Jacobs et al., 2016; McCullough \& Matson, 2012), there are few theories or practical lessons of how to ensure coproduced knowledge facilitates action (Blackstock, Kelly, \& Horsey, 2007; Polk, 2014; van Kerkhoff \& 
Lebel, 2006; Wiek, Ness, Schweizer-Ries, Brand, \& Farioli, 2012; Wuelser \& Pohl, 2016). Without greater emphasis on the ways in which knowledge co-production is translated to action, researchers and practitioners may be limited in their ability to implement solutions to sustainability challenges.

Transdisciplinary approaches provide an opportunity, in particular, for improving land-use planning and policy actions (Maiello, Battaglia, Daddi, \& Frey, 2011; Schauppenlehner-Kloyber \& Penker, 2015; Zscheischler \& Rogga, 2015). While private land use is regulated at federal and state levels in the US, the political, economic and ecological dynamics surrounding land use often play out at the municipal level (Brody, Highfield, \& Carrasco, 2004; Feiock, Tavares, \& Lubell, 2008; Gerber \& Rissman, 2012; Levesque, Bell, \& Calhoun, 2017). The complexity and interconnectivity of the social, economic and environmental issues surrounding private land development make it a classic sustainability challenge. Agriculture, homes and businesses provide us with the food, shelter and goods on which we rely and enjoy as a society. Yet the conversion of natural and semi-natural landscapes to create these goods is a leading cause of habitat fragmentation and loss (Hunter, 2005; Stokes, Hanson, Oaks, Straub, \& Ponio, 2009; Wilcove \& Lee, 2004). The use of growth control regulations to limit environmental impacts gives rise to conflicts about important economic and social benefits of development, as well as the extent and manner by which property rights should be limited (Doremus, 2003; Irwin, Bell, \& Geoghegan, 2003; Paloniemi \& Tikka, 2008). Additionally, with a recent focus on complementing or replacing traditional zoning with market- or incentive-based strategies to protect resources (Beeton \& Lynch, 2012; Norton, 2000; Paloniemi \& Tikka, 2008; Pirard, 2012; Shortle, 2013), municipal leaders may lack expertise in assessing alternative instruments of land protection within the context of their municipality (Hockenstein et al., 1997). Transdisciplinary approaches can advance existing collaborations between land use planners and researchers interested in identifying and applying new information to innovative solutions (Zscheischler \& Rogga, 2015). 


\section{The transdisciplinary approach to linking knowledge to action}

The transdisciplinary research process is often conceptualized as three interrelated phases: (1) building a collaborative team consisting of academic and non-academic stakeholders and jointly framing the problem, (2) co-producing problem-specific knowledge, and (3) integrating and applying the coproduced knowledge by both scientists and practitioners (Binder et al., 2015; Godemann, 2008; Lang et al., 2012). Sustainability scientists have greatly advanced the understanding of these processes in the last decade. For example, Clark et al. (Clark, van Kerkhoff, et al., 2016) illuminates key things researchers should know and should do related to creating usable knowledge, which is knowledge produced to facilitate decision-making related to a specific societal problem (Dilling \& Lemos, 2011). However, while difficulties emerge in each of the three phases, the biggest challenges in the process often stem from an inability to link knowledge produced to planning and decision-making processes such that change occurs, even when the knowledge produced could be deemed 'usable' and socially robust (Polk, 2014). Much less emphasis has gone into understanding how to conceptualize and overcome these challenges.

We reviewed existing literature that analyzed how knowledge supported action within transdisciplinary approaches to solving problems to identify factors that limit the degree to which coproduced knowledge was applied to a new action or solution on-the ground, and we synthesized the information about these factors to develop four broad categories that represent major challenges to connecting knowledge to new action (Table 1). First, individuals in heterogeneous groups need to both transfer their knowledge to others as well as enlarge their perspectives to value and assimilate others' information into their own knowledge structures (Godemann, 2008; Polk, 2015). Second, groups often need to develop common conceptualizations of their complex problem to develop innovative solutions (Binder et al., 2015; Godemann, 2008; Harris \& Lyon, 2013). Third, even when joint learning occurs, there is often no explicit link to specific planning and decision contexts, creating a gap between new knowledge and new action (Polk, 2014). Fourth, when transdisciplinary processes do develop solutions, 
those proposed actions may lack legitimacy when transferred back to specific decision-making bodies

(Binder et al., 2015; Clark, van Kerkhoff, et al., 2016; Hart \& Calhoun, 2010; Lang et al., 2012; Polk,

2014). If transdisciplinary processes truly occur in an intermediary space between academia and policy

or if the processes do not include participants with decision-making authority in their own sphere, the

results of such efforts may not be viewed as belonging to either sphere when brought back; rather,

results often must be re-framed and re-packaged in ways that speak to different contexts such that they

will be accepted in these disparate institutional settings (Polk, 2014).

Table 1: Challenges in linking co-produced knowledge to new action in transdisciplinary research

\begin{tabular}{|c|c|c|}
\hline Challenge & Description & Key literature \\
\hline $\begin{array}{l}\text { Integrated } \\
\text { knowledge }\end{array}$ & $\begin{array}{l}\text { Members of diverse groups transfer their knowledge to } \\
\text { others, and value, understand and assimilate other's } \\
\text { information and perspectives. Participants may differ in } \\
\text { what they believe to be relevant knowledge, or they may } \\
\text { lack the time required for true understanding and } \\
\text { integration of new information. }\end{array}$ & $\begin{array}{l}\text { Godemann, 2008; } \\
\text { Polk, } 2015\end{array}$ \\
\hline $\begin{array}{l}\text { Joint mental } \\
\text { models }\end{array}$ & $\begin{array}{l}\text { Members create shared conceptualizations of the problem } \\
\text { and interrelated issues. To do so, group processes should } \\
\text { foster trust, norms, shared power, social learning, among } \\
\text { other factors. }\end{array}$ & $\begin{array}{l}\text { Binder et al., 2015; } \\
\text { Godemann, 2008; } \\
\text { Harris \& Lyon, 2013 }\end{array}$ \\
\hline $\begin{array}{l}\text { Explicit link } \\
\text { between new } \\
\text { knowledge and } \\
\text { specific } \\
\text { decision }\end{array}$ & $\begin{array}{l}\text { Group identifies where and what type of decisions are } \\
\text { needed for action. Complications arise when new } \\
\text { knowledge is not translated into recommended actions, } \\
\text { specific decision points are not identified, or decisions } \\
\text { occur on a different time scale than the collaborative } \\
\text { process. }\end{array}$ & Polk, 2014 \\
\hline $\begin{array}{l}\text { Legitimate } \\
\text { solutions }\end{array}$ & $\begin{array}{l}\text { Partners ensure proposed solutions will be deemed } \\
\text { legitimate. The participants may not have decision-making } \\
\text { authority or political mandate, power imbalances may } \\
\text { cloud implementation efforts, or results may not be } \\
\text { reframed for different settings. }\end{array}$ & $\begin{array}{l}\text { Binder et al., 2015; } \\
\text { Clark, van Kerkhoff, et } \\
\text { al., 2016; Hart \& } \\
\text { Calhoun, 2010; Lang } \\
\text { et al., 2012; Polk, } \\
2014\end{array}$ \\
\hline
\end{tabular}

This paper analyzes how transdisciplinary research can facilitate action by analyzing the creation of a new market-based mechanism for conserving vernal pool ecosystems in Maine, USA (Removed for review). We demonstrate that knowledge was co-produced, and then we ask (1) Was the co-produced 
knowledge used in developing a solution in this case; and (2) If so, how did the transdisciplinary process overcome the four common challenges to using co-produced knowledge? Our case contributes to the growing body of inquiry in sustainability science that assesses the on-the-ground challenges and successes of linking knowledge to action in transdisciplinary research as applied to land-use planning and policy.

\section{Case Study Context}

This research focuses on a transdisciplinary effort to create a new instrument for conserving vernal pools at the municipal scale in Maine, USA. Vernal pools in the northeastern United States are ephemeral wetlands that provide breeding habitat to amphibian and invertebrate species adapted to life in fishless, temporary waters, resting or foraging habitat to a suite of other species, and ecosystem system functions related to hydrology, water quality and biogeochemical processes (Calhoun et al., 2017; Calhoun \& deMaynadier, 2008; Colburn, Weeks, \& Reed, 2008; Golden et al., 2017). The role of vernal pools in maintaining thriving amphibian populations depends on the quality of their connectivity to neighboring post-breeding terrestrial habitats and other wetlands. Therefore, not only are vernal pools themselves at high risk of loss or degradation from development, but pool ecosystem functions, including wildlife habitat for other species and energy flow from wetlands to uplands, can be compromised by landscape fragmentation (Baldwin \& deMaynadier, 2009; Cohen et al., 2016). Approximately $94 \%$ of Maine's land area is privately owned (LeVert, 2008), so private landowner actions can have significant impacts on vernal pool ecosystems in this region.

Existing vernal pool regulations are standards that apply equally to all landowners whose vernal pools meet specific criteria. In New England, the Army Corps of Engineers (ACOE) reviews development around vernal pools on properties where waters of the US will be dredged or filled. In addition, the State of Maine regulates land conversions within 250 feet of a subset of exemplary vernal pools. While these regulations provide a minimal level of protection to a resource that was traditionally overlooked, they 
have ecological, economic and social shortcomings. They will likely fail to conserve the functional integrity of vernal pool ecosystems as terrestrial and wetland connectivity is increasingly fragmented (Baldwin \& deMaynadier, 2009; Bauer, Paton, \& Swallow, 2010; Aram J. K. Calhoun et al., 2014; Freeman, Bell, Calhoun, \& Loftin, 2012). Furthermore, Maine regulations currently regulate fewer than $25 \%$ of all vernal pools documented in the state vernal pool database (P.deMaynadier, Maine Department of Inland Fisheries and Wildlife pers. comm.). Additionally, some landowners feel unduly burdened by their reduced development options (Jansujwicz, Calhoun, \& Lilieholm, 2013), and some town planning staff report that proposed development projects in designated growth areas were withdrawn due to vernal pool regulations, resulting in the loss of valuable economic development. These conflicting views led to a highly contentious political context surrounding vernal pool regulations (Levesque et al., 2017). For more information about vernal pool ecology and regulations, see http://www.vernalpools.me/.

Vernal pool conservation efforts highlight tensions between the protection of public goods and the rights of property owners, a tendency to focus on individual projects rather than cumulative impacts and landscape-scale processes, a multi-layered and fragmented regulatory system, and a lack of consideration of how future build-out scenarios could affect ecosystems. Thus, the difficulties associated with vernal pool conservation are representative of other planning challenges involving natural resource regulation on private land (Bauer, Bell, Nelson, \& Calhoun, 2017; Calhoun et al., 2014; Quinn \& Wood, 2017; Shogren, 2005).

To address the regulatory and land-use planning challenges associated with vernal pools, the authors of this paper engaged key stakeholders to discuss and develop alternative vernal pool mitigation strategies from 2010 through 2017 (for more details of the context and process, see Removed for review). Approximately 25 individuals representing two municipalities, four state agencies, three federal agencies, two land trusts, development and real estate interests, private consultants, and university 
researchers actively participated in the development of an alternative mechanism for conserving vernal pools at the municipal scale. All three authors per were active participants in this project. (Name redacted for review) was a doctoral student and former town natural resources planner and conducted the policy simulation reported in this paper. (Name redacted for review) served as a coordinator of, as well as a wetland ecologist expert in the project, and (Name redacted for review) oversaw much of the economic analysis and engagement with the development community. The following is a brief summary of the three phases of the transdisciplinary process used to develop a new mechanism for conserving vernal pools.

\section{Phase 1: Group creation and problem definition}

The stakeholders met regularly over the course of six years in large group meetings to discuss and develop the new mechanism, as well as in smaller subgroups that formed as needed (Table 2). These meetings occurred throughout the project region, primarily at town halls and state office buildings. The first meeting was organized by a researcher and included state and federal regulators and a municipal representative - for a total of 7 participants. There were 21 meetings in the first two years (both full and sub-group meetings), with new participants invited to 15 of those meetings; in other words, the first two years were characterized by a continual expansion of the group as new perspectives and types of knowledge were needed. For example, some of the early meetings focused on bringing in more municipal representatives because it was recognized that their on-the-ground knowledge as well as their political will would be essential to creating a municipal-scale policy mechanism. Similarly, towards the end of the second year, a group of developers were brought into the process when the group realized that their experience with existing regulations and reaction to proposed concepts was missing. The first two years were also characterized by a focus on (re)defining the scope of the problem and embracing a common goal (e.g., deciding to tackle only vernal pools and not on other resources; 
focusing on the municipal-scale). At the same time, the group was discussing different possible solutions and gathering initial information needed to explore those options.

Table 2: Transdisciplinary research phases of the vernal pool regulatory mechanism process

\begin{tabular}{|c|c|c|c|c|c|}
\hline $\begin{array}{l}\text { Phase } \\
1\end{array}$ & $\begin{array}{l}\text { Phase } \\
2\end{array}$ & $\begin{array}{l}\text { Phase } \\
3\end{array}$ & Year & $\begin{array}{l}\text { New } \\
\text { partners } \\
\text { added }\end{array}$ & Primary outcomes \\
\hline & & & 2010 & 9 & $\begin{array}{ll}\text { - } & \text { Expanded stakeholder group } \\
\text { - } & \text { Identified problems } \\
\text { - } & \text { Explored many possibly policy solutions } \\
\end{array}$ \\
\hline & & & 2011 & 10 & $\begin{array}{l}\text { - } \quad \text { Built trust \& shared language in expanding group } \\
\text { - } \quad \text { Established subgroups } \\
\text { - } \quad \text { Identified economic and ecological data needs } \\
\text { - } \quad \text { Conducted initial research } \\
\text { - } \quad \text { Some strong debates over details }\end{array}$ \\
\hline & & & 2012 & 4 & $\begin{array}{ll}\text { - } & \text { Subgroups created detailed information } \\
\text { - } & \text { Drafted initial details of policy mechanism } \\
\text { - } & \text { Outlined the SAMP }\end{array}$ \\
\hline & & & 2013 & 3 & $\begin{array}{l}\text { - } \quad \text { Small groups provided focused contributions to } \\
\text { - } \quad \text { Ppecific aspects of the new mechanism } \\
\text { - } \quad \text { Wrote SAMP as details were determined } \\
\end{array}$ \\
\hline & & & 2014 & & $\begin{array}{ll}\text { - } & \text { Full policy simulation results reported and revised } \\
\text { - } & \text { Revisited some decisions \& new decisions made } \\
& \text { levels to implement mechanism }\end{array}$ \\
\hline & & & $\begin{array}{l}2015- \\
2016\end{array}$ & & $\begin{array}{l}\text { - } \quad \text { Draft SAMP finalized, reviewed \& revised } \\
\text { - } \\
\text { - } \\
\text { Identified implementation steps at town and state } \\
\text { levels }\end{array}$ \\
\hline & & & 2017 & & $\begin{array}{l}\text { - } \quad \text { Focused efforts to facilitate town implementation } \\
\text { - } \quad \text { Applied for new funding for implementation } \\
\text { - } \quad \text { Educated staff at partner organizations about SAMP }\end{array}$ \\
\hline
\end{tabular}

Phase 2: Co-production of knowledge

As the process progressed, more effort was spent on gathering information needed to create a new policy mechanism. This work was often completed by the subgroups, a "divide and bring back 
together" approach that allowed experts to resolve internal differences within subgroups and report unanimously supported information to the larger group for deliberation. For example, developers and economists worked together to explore financial implications of existing and proposed regulations, while biologists and regulators met to identify the essential ecological conditions for conserving vernal pool systems while meeting the missions of state and federal regulatory agencies. Other times, individual group members would prepare information for presentation and discussion with the larger group. For example, an appraiser carried out a mock appraisal of a property with and without a vernal pool, which the larger group used to explore ways to implement an impact fee.

This paper focuses on a policy simulation effort that emerged from within the collaborative process. The group desired an incentive-based instrument tailored to the specific ecological and economic conditions of the individual municipalities that adopt it. As they discussed what a new mechanism would look like, questions regarding its feasibility and likely outcomes as compared to existing regulations emerged. In response to these questions, we simulated economic and ecological outcomes of the existing federal and state regulations and of the proposed market-based mitigation mechanism in two Maine municipalities. We completed a series of simulations, iteratively providing results to get feedback for refining the simulations and asking participants for what additional information would be salient. When presenting simulation results, we openly discussed their limitations such as the limited availability of detailed municipal-scale and vernal pool data, and the challenges of predicting future conservation costs.

The simulations suggested that that the proposed market-based mechanism would incur greater total costs than the existing vernal pool regulations. However, under the proposed market mechanism, both the estimated landowner costs and governmental administrative costs were lower as compared to the existing regulations, while land trusts took on new and substantial costs of negotiating, purchasing and managing conservation easements. The simulations also indicated that in both municipalities, a 
much larger area of higher quality amphibian habitat would be protected (in perpetuity) under the market mechanism as compared to the existing vernal pool regulations. However, in our analysis, there were not enough pre-identified mapped vernal pools and surrounding mitigation land in the rural area to meet the specified criteria to mitigate for the loss of growth area vernal pools in either town. Lastly, our policy simulations consistently raised questions about the ability of the impact fees set by to group to cover the costs of mitigation.

\section{Phase 3: Applying co-produced knowledge}

The result of this transdisciplinary process was new policy action: A Vernal Pool Special Area Management Plan (SAMP) that enabled the ACOE and the State of Maine to allow municipalities to use the new mechanism if the municipalities met a list of criteria (see the SAMP for details http://www.nae.usace.army.mil/Missions/Regulatory/Vernal-Pools/). The SAMP underwent public review and public comment in March 2016 before being revised and adopted in September 2016. As of spring 2018, one municipality had adopted the necessary local ordinances and state regulatory delegation to implement this mechanism, and another is in the process of doing so.

\section{Methods}

In this transdisciplinary process, we interacted fully with the broader stakeholder group and were engaged in the process from problem definition to policy creation (Brandt et al., 2013; Wiek et al., 2012). We employ a qualitative case study approach to explore how co-produced knowledge was used to shape a new land use policy (Yin, 2009). Case study methodology can be most effective when used to deeply explore contextual details, while employing transparent analytical methods and theoretical approaches (Corcoran et al., 2004). We relied on two data sources within our case study: documents and participant observation field notes. We maintained electronic files of the documents created and 
used during the process, including all versions of the draft vernal pool protection mechanism. We also took detailed notes during and after meetings of the collaborative group that record what happened and our reflections on the process.

While there were many types of knowledge created during this multiyear process, this paper focuses on the policy simulation exercise conducted to compare potential ecological and economic outcomes of the proposed policy mechanism to the existing regulations. Our analysis for this paper includes a comparative assessment of the text of the draft proposed mechanism at the time of the policy simulation to the final version of the mechanism that went out for public comment in March 2016 in order to identify major modifications in the policy mechanism. We then assessed the major modifications for linkages to specific results of the policy simulations discussed by the larger group (and recorded in our field notes.) To analyze our participant observation notes, we identified text related to information creation, simulation results, interpretation and discussion of results, and policy formulation, and we categorized this text into themes. Our themes were informed by the transdisciplinary research and knowledge-to-action literature, and were used to identify factors that enabled the group to use simulation results in new policy creation. The on-the-ground process discussed in this paper was not informed by the literature at the time of the project; it is only in retrospect that we explore and apply theoretical concepts to the process in which we were engaged.

\section{Results}

We found that the co-produced policy simulation information shaped the details of the final vernal pool policy mechanism. There are several substantive differences between the draft vernal pool conservation mechanism and the final version that went out for public comment in the Federal Register in March 2016 which are attributable to the knowledge that developed during policy simulations. First, in recognition of the increased administrative costs to land trusts for the negotiation, purchase, and 
monitoring of vernal pool conservation easements, the final mechanism allows for a trust to use up to $10 \%$ of collected impact fees to cover project implementation. Second, since mitigation options were found to be limited within the municipality where vernal pools are impacted, the final mechanism provides an option for conservation funds to be applied, in order of preference, within the rural areas of town where impacts occurred, within the rural areas of adjacent towns that meet specific criteria, and within the geographic area of interest for the land trust (or other third party) administering the funds. Third, because simulation results suggested that the impact fee desired by some group members would not cover the costs of required mitigation, the impact fee in the final mechanism was higher than what was initially proposed, and the SAMP articulates an annual review of conservation deals to assess and alter, if necessary, future impact fees.

\section{Factors that facilitated linking knowledge to action}

We explored the aspects of the transdisciplinary research process that facilitated use of coproduced knowledge in policy development. Our results fall into four primary themes: a culture of learning, policy simulations as co-produced boundary objects, integrating research into solution development, and an adaptive, iterative management approach.

Culture of learning. This process was characterized by a culture of learning in which both researcher and stakeholder knowledge was equally sought-after, valued and incorporated into new policy. One of the key features of this case is that new partners were engaged as new knowledge or perspectives were needed. For example, developers were invited to participate, and they worked in a subgroup in tandem with university economists and municipal economic development professionals to compile information, debate results and present consensus ideas to the larger group.

This example supports a finding of a culture of learning in multiple ways. Stakeholder knowledge (developers and municipal officials) was valued equally with researcher-provided data. Even though the 
addition of new members slowed the process (as new members learned terminology, questioned the problem definition, built trust), the ethos of the group was to embrace new knowledge and perspectives. Subgroups provided an opportunity for the in-depth examination of detailed data and dissent about their meaning within a focused, safe environment. Lastly, when sub-group ideas were brought back to the full group, they were discussed in relation to their application to the new policy mechanism, providing an opportunity for others in the group to learn and actively debate how to tailor the mechanism. While not always a smooth process, these give-and-take conversations were infused with a desire to understand each other's information and build upon it.

One additional benefit of the culture of learning in this project was that participants reported feeling valued for their contributions, which helped maintain momentum in a multi-year process. Participants' direct involvement in developing knowledge in subgroups and incrementally developing a new mechanism as a large group helped keep participants engaged, along with more traditional measures such as regular meetings with food, email updates and ground rules that engendered respect.

Policy simulations as co-produced boundary objects. The simulations of future conditions under existing and proposed vernal pool regulations provided more than new knowledge. Notably, the simulations were co-produced; by their very nature, they required information from both academics (e.g., vernal pool ecological data, economic modeling) and non-academics (e.g., municipal zoning, developer financial information). Additionally, because modeling of future scenarios requires making some assumptions and is based on incomplete data, many decisions were made (e.g., preferred characteristics of properties to conserve) through group discussions.

Further, the simulations were conducted in multiple rounds of increasing complexity, with discussion about their meaning, usefulness, and suggestions for improvements. In these deliberations, the simulations results (in the form of maps, tables and presentations) provided a common touch stone for everyone to conceptualize the problem and related issues. For example, one of the problems with 
the existing regulations is that they may hinder development in areas where municipalities want to promote growth, driving those developments either to another more rural site (creating sprawl) or to other towns (losing local tax revenue). While this problem was one of the original reasons for a wide range of participants to join this project, because the simulations required a specific delineation of where these growth areas would be in each town, they became a way for the group members to hash out what they were really concerned about and to float ideas about how to design the new mechanism to address the refined problem. Hence, the simulations themselves acted as boundary objects that allowed participants from different perspectives to describe the problems through their own lens while also being able to create a joint conceptualization of the project (Clark, Tomich, et al., 2016). Integrating research into solution development. The collaborative group started brainstorming possible solutions to the identified problems in the earliest meetings. The initial conceptualization of solutions then drove the development of new knowledge. In the first couple of years, that new knowledge was the compilation of existing information: stories exemplifying the problem; examples of innovative policy solutions; maps of known vernal pool locations. As the new mechanism was further developed, more specific new knowledge was needed. The policy simulations, for example, were developed in response to questions about how outcomes of the proposed mechanism would compare to existing regulations.

Information production was part of a cyclical process of coming up with solution options, compiling or creating information that would help advance the development of the solution, further refining of the proposed mechanism based on deliberation of the new knowledge, and so on. Further, because there was a continual focus on developing a solution, researchers themselves were embedded into the decision-making process so that they were engaged in discussions about needed information and about how new knowledge could be applied to the policy. For example, economists on the team conducted a follow-up sensitivity analysis of more than 1,000 scenarios to provide additional 
information to the group about likely outcomes of the proposed mechanism that they could use when refining the policy.

Thus, the process of applying co-produced knowledge to creating a new solution was an iterative, on-going practice rather than something that happened at the end of the process. The research and knowledge co-production pieces were intimately tied to and embedded in a specific policy development effort. With this foundation, the project leads remained involved in facilitating implementation as the final step of the process.

Adaptive management approach. This transdisciplinary research process incorporated adaptive management strategies within its operation as well as within the final solution that was adopted. Policy development occurred over multiple years, during which knowledge production itself evolved as new perspectives emerged. Further, even though policy solutions were discussed early on, the group remained open to adjusting aspects that they felt could be improved. When stumbling blocks arose, the group brainstormed options, debated controversial issues and found ways to compromise when needed. For example, there were points in the process when it was unclear how the manage the fact that different regulatory vehicles exist at municipal, state and federal levels, and there were not obvious ways to allow them to work together. The collaborative group responded by discussing options and adapting the proposed solution to meet the needs of each agency. Several factors likely enabled this adaptive approach: there were participants from each level of governance that had participated since the conception of the project and had committed to its success; the project coordinator created an atmosphere of problem-solving and experimentation; and trust and power sharing had developed among group members to the level that they were willing to compromise and to support the proposal despite uncertainty (Removed for review).

Furthermore, the new mechanism incorporated two key adaptive management features: a monitoring system to keep track of progress and a provision to review local outcomes annually and 
project outcomes in five years to determine whether to continue, revise or discontinue the mechanism. Given the uncertainty in both the economic and ecological outcomes of the proposed mechanism, the fact that the policy would be reviewed within these two timeframes allowed group members to move forward in applying co-produced but inherently limited knowledge to solution-creation. This learning-bydoing approach mirrored the iterative process of developing the new mechanism, and built into the program an opportunity for reflection and revision.

\section{Discussion}

In this study, we explored a transdisciplinary research process to develop an alternative land use mitigation mechanism for conserving vernal pool systems while enabling growth area development. We found that specific knowledge co-produced during the process was used in shaping the final policy mechanism. We identified four key characteristics of this process that address the known challenges of linking new co-produced knowledge to action: creating a culture of learning, policy simulations as boundary objects, integrating research into solution development, and an adaptive management approach (Table 3).

When a culture of learning pervades a transdisciplinary research project, participants are freed from the need to know and to be experts, and can share and learn from each other. We call it a culture of learning to stress the idea that the learning needs to go beyond a cursory exercise or formal presentation of material. These results support Clark et al. (2016) who state that individual researchers should focus on learning, not knowing, and thus shift from an individualistic, competitive stance to an integrative, cooperative one. We build on this by suggesting it is not just the researchers who benefit from this shift, but all participants. It was just as helpful for the developers in the room to learn why the ecologists were excited about the annual amphibian "Big Night" migration to breeding pools, as it was for the economists to learn how the towns assign property values. Similarly, Clark et al. (2016) discuss 
the importance of universities and other organizations to be safe spaces that reward experimentation

that promotes social learning. While this remains as essential, we show that the transdisciplinary

approach itself can also be designed to be a safe space that encourages learning from each other, and

allowing for the integrated knowledge that is necessary to connect the new knowledge to action.

Table 3: Ways in which the vernal pool transdisciplinary approach addressed major challenges in connecting knowledge to action

\begin{tabular}{|l|l|}
\hline Challenge & Strategies used to address challenge \\
\hline knowledge & $\begin{array}{l}\text { A culture of learning valued and integrated multiple types of academic and } \\
\text { non-academic knowledge. Small workgroups provided a forum for the } \\
\text { exploration and synthesis of in-depth knowledge. Deliberative processes in } \\
\text { large groups ensured participants shared information as well as worked to } \\
\text { understand, synthesize and assimilate others' perspectives and information. }\end{array}$ \\
\hline Joint mental models & $\begin{array}{l}\text { The policy simulations became co-produced boundary objects that } \\
\text { incorporated information and feedback from all participants and that } \\
\text { provided a common object with which they could understand the entirety of } \\
\text { the problem and see their own perspective reflected. The co-production } \\
\text { process used built upon the trust, shared power, and social learning that had } \\
\text { been fostered in the collaborative group. }\end{array}$ \\
\hline $\begin{array}{l}\text { Explicit link between } \\
\text { new knowledge and } \\
\text { specific decision }\end{array}$ & $\begin{array}{l}\text { Research was directly integrated into solution development from the earliest } \\
\text { stages of the transdisciplinary process. The very debates over the details } \\
\text { about the proposed solution helped the group stay focused on compiling and } \\
\text { analyzing relevant information. Rather than creating a link between new } \\
\text { information and a possible solution at the end of the process, the translation } \\
\text { of knowledge into policy action was incorporated from the beginning. }\end{array}$ \\
\hline Legitimate solutions & $\begin{array}{l}\text { An adaptive management approach allowed for iterative ground-truthing of } \\
\text { the viability and legitimacy of the proposed mechanism for each party } \\
\text { involved in implementation. Including both the regulated and the regulators } \\
\text { equally in generating the solution helped reduce power imbalances. } \\
\text { Additionally, there were explicit discussions about what tools could be } \\
\text { utilized at each level of governance. The solution itself incorporated adaptive } \\
\text { management provisions, to encourage improvement over time and manage } \\
\text { uncertainty. }\end{array}$ \\
\hline
\end{tabular}

Our finding that the policy simulations acted as boundary objects addresses the challenge of

having a diverse group find common ground and joint mental models. The boundary work literature is

rich with examples of how objects can provide these joint models (see for example (Cash et al., 2003;

Clark, Tomich, et al., 2016; Guston, 2001; Kirchhoff, Carmen Lemos, \& Dessai, 2013). In this case, there 
was no explicit boundary organization or overt attempt to create a boundary object. However, due to the intense co-production of the policy simulations, with input of data from many participants and multiple opportunities to discuss the meaning of results, the simulations became a touchstone around which participants could discuss their particular concerns and debate policy aspects. Prior to the actual SAMP being written that spelled out the details of the new mechanism, the policy simulations (as associated maps and tables) acted as representations of the proposed solution and allowed the type of shared understanding that is necessary for creating concrete refinements.

Drawing on the framework created by Clark et al. (Clark, Tomich, et al., 2016), the source knowledge in this case was multiple communities of expertise (versus a single expert) for the purpose of negotiating a new solution. Clark et al. suggest that the boundary work or object must be salient, credible and legitimate to aid in a negotiation process. We found that policy simulations were salient; they responded directly to requests for this information. They were credible; the simulations incorporated data from all members, the limitations were discussed and not glossed over, and the group had developed trust for each other and the process. Finally, the simulations were considered legitimate, unbiased representations of the policy outcomes. This legitimacy was partly established through a transparent and iterative process in which participants could understand how maps and figures were created.

Rather than creating a link between new information and a possible solution at the end of the process, the translation of knowledge into policy action was incorporated throughout this transdisciplinary process, within recursive loops. By revising the policy as knowledge emerged during the transdisciplinary research process, members came to expect and ensure that new information and perspectives would continue to inform policy creation. Information was produced for the explicit purpose of refining a proposed solution: whether it was the policy simulation on which we focused in this paper, or other new information such the mock appraisal that tested whether an impact fee based 
on appraised values could work. At the same time, project leaders remained engaged throughout the final steps of getting the SAMP approved and actively facilitating implementation at the local level, not withdrawing after the 'research' components were complete. We suggest that, in practice, the three phases of transdisciplinary research should ideally overlap and interact with each other. Thus, our results support van Kerkoff and Lebel (2006) who suggest that knowledge connects to action within an arena of interaction. When the relationship between co-produced knowledge and action is understood as an arena (as opposed to a linear link), there is room to explore the myriad factors that encourage action throughout transdisciplinary research processes (van Kerkhoff \& Lebel, 2006).

An adaptive management approach also linked knowledge to action, both by providing a tool for managing uncertainty (Jacobs et al., 2016) and by ensuring the solution would be legitimate in specific decision arenas. Simulating complex human behavior using regression models has limitations, and although our simulation used the best available data, was adjusted to address stakeholder questions, and was followed with subsequent rounds of modeling, results were still uncertain. Others have suggested that uncertainty and risk in market mechanisms can affect the implementation of such instruments (BenDor, 2009; BenDor, Riggsbee, \& Doyle, 2011). While it remains to be seen how uncertainty will affect policy implementation in this instance, the awareness that the new mechanism would be monitored, reviewed, and adjusted allowed skeptics to support the policy and facilitated the acceptance of the policy within the necessary local, state and federal entities. Further, the review requirements built into the mechanism itself helped individual stakeholders when they returned to their respective spheres (e.g. municipal governments, state and federal regulator agencies) to convince their peers of the ability to revise the mechanism in the near future if deemed ineffective; this helped these actors demonstrate the legitimacy of the new mechanism in their own spaces.

\section{Conclusion: A Way Forward}


In this case, we identified four aspects of the process that helped overcome common challenges to acting upon new information. We suggest that, at least in some cases, embedding knowledge creation within and throughout an on-going effort to seek and develop solutions is an essential ingredient. Within this arena of interaction, instilling a culture of learning, co-produced boundary objects, and an adaptive management approach will further facilitate the use of new knowledge. It was not our intent to do a full analysis of the transdisciplinary process, nor have we fully analyzed the many challenges along the way, such as how the group maintained momentum over such a long time frame. Rather, we were interested in pulling out key features of a specific case that could provide insight into the ways in which knowledge facilitates action. Although there may not be many documented analyses of what facilitates the use of co-produced knowledge in developing solutions, it is likely that there are many projects in which this transfer occurs, in which different approaches may address the known challenges to linking knowledge with action. With an increased focus on identifying the key factors that enable acting on solutions, we can develop the same level of nuanced theoretical concepts currently characterizing the earlier phases of transdisciplinary research, and the practical advice for deliberately designing these efforts.

\section{$\underline{\text { References }}$}

Baldwin, R. F., \& deMaynadier, P. G. (2009). Assessing threats to pool-breeding amphibian habitat in an urbanizing landscape. Biological Conservation, 142(8), 1628-1638. http://doi.org/10.1016/j.biocon.2009.02.039

Bauer, D. M., Bell, K. P., Nelson, E. J., \& Calhoun, A. J. K. (2017). Managing small natural features: A synthesis of economic issues and emergent opportunities. Biological Conservation, 211, 80-87. http://doi.org/10.1016/j.biocon.2017.01.001

Bauer, D. M., Paton, P. W. C., \& Swallow, S. K. (2010). Are wetland regulations cost effective for species protection? A case study of amphibian metapopulations. Ecological Applications, 20(3), 798-815. Retrieved from http://www.ncbi.nlm.nih.gov/pubmed/20437965

Beeton, R. J. S., \& Lynch, A. J. J. (2012). Most of nature: A framework to resolve the twin dilemmas of the decline of nature and rural communities. Environmental Science \& Policy, 23, 45-56. http://doi.org/10.1016/j.envsci.2012.07.009

BenDor, T. K. (2009). A dynamic analysis of the wetland mitigation process and its effects on no net loss 
policy. Landscape and Urban Planning, 89(1-2), 17-27.

http://doi.org/10.1016/j.landurbplan.2008.09.003

BenDor, T. K., Riggsbee, J. A., \& Doyle, M. (2011). Risk and markets for ecosystem services. Environmental Science \& Technology, 45(24), 10322-30. http://doi.org/10.1021/es203201n

Binder, C. R., Absenger-Helmli, I., \& Schilling, T. (2015). The reality of transdisciplinarity: a frameworkbased self-reflection from science and practice leaders. Sustainability Science, 10(4), 545-562. http://doi.org/10.1007/s11625-015-0328-2

Blackstock, K. L., Kelly, G. J., \& Horsey, B. L. (2007). Developing and applying a framework to evaluate participatory research for sustainability. Ecological Economics, 60(4), 726-742. http://doi.org/10.1016/j.ecolecon.2006.05.014

Brandt, P., Ernst, A., Gralla, F., Luederitz, C., Lang, D. J., Newig, J., ... Von Wehrden, H. (2013). A review of transdisciplinary research in sustainability science. Ecological Economics, 92, 1-15. http://doi.org/10.1016/j.ecolecon.2013.04.008

Brody, S. D., Highfield, W., \& Carrasco, V. (2004). Measuring the collective planning capabilities of local jurisdictions to manage ecological systems in southern Florida. Landscape and Urban Planning, 69(1), 33-50. http://doi.org/10.1016/j.landurbplan.2003.09.002

Buizer, J., Jacobs, K., \& Cash, D. W. (2016). Making short-term climate forecasts useful: Linking science and action. Proceedings of the National Academy of Sciences of the United States of America, 113(17), 4597-4602. http://doi.org/10.1073/pnas.0900518107

Calhoun, A. J. K., \& deMaynadier, P. G. (2008). Science and conservation of vernal pools. Boca Raton, FL: CRC Press.

Calhoun, A. J. K., Jansujwicz, J. S., Bell, K. P., \& Hunter, M. L. (2014). Improving management of small natural features on private lands by negotiating the science-policy boundary for Maine vernal pools. Proceedings of the National Academy of Sciences of the United States of America, 111(30), 11002-11006. http://doi.org/10.1073/pnas.1323606111

Calhoun, A. J. K., Mushet, D. M., Alexander, L. C., DeKeyser, E. S., Fowler, L., Lane, C. R., ... Walls, S. C. (2017). The Significant Surface-Water Connectivity of "Geographically Isolated Wetlands." Wetlands. http://doi.org/10.1007/s13157-017-0887-3

Cash, D. W., Clark, W. C., Alcock, F., Dickson, N. M., Eckley, N., Guston, D. H., ... Mitchell, R. B. (2003). Knowledge Systems for Sustainable Development. Proceedings of the National Academy of Sciences of the United States of America, 100(14), 8086-8091. http://doi.org/10.1073/pnas.1011602108

Clark, W. C. (2007). Sustainability science: a room of its own. Proceedings of the National Academy of Sciences of the United States of America, 104(6), 1737-8. http://doi.org/10.1073/pnas.0611291104

Clark, W. C., \& Dickson, N. M. (2003). Sustainability science: the emerging research program. Proceedings of the National Academy of Sciences of the United States of America, 100(14), 805961. http://doi.org/10.1073/pnas.1231333100

Clark, W. C., Tomich, T. P., van Noordwijk, M., Guston, D. H., Catacutan, D., Dickson, N. M., \& McNie, E. (2016). Boundary work for sustainable development: Natural resource management at the Consultative Group on International Agricultural Research (CGIAR). Proceedings of the National Academy of Sciences of the United States of America, 113(7), 4615-4622. http://doi.org/10.1073/pnas.0900231108

Clark, W. C., van Kerkhoff, L., Lebel, L., \& Gallopin, G. C. (2016). Crafting usable knowledge for 
sustainable development. Proceedings of the National Academy of Sciences, 113(17), 4570-4578. http://doi.org/10.1073/pnas.1601266113

Cohen, M. J., Creed, I. F., Alexander, L., Basu, N. B., Calhoun, A. J. K., Craft, C., ... Walls, S. C. (2016). Do geographically isolated wetlands influence landscape functions? Proceedings of the National Academy of Sciences of the United States of America, 113(8), 1-9. http://doi.org/10.1073/pnas.1512650113

Colburn, E., Weeks, S. C., \& Reed, S. K. (2008). Diversity and ecology of vernal pool invertebrates. In A. J. K. Calhoun \& P. G. DeMaynadier (Eds.), Science and Conservation of Vernal Pools in Northeastern North America (pp. 107-124). Boca Raton, FL: CRC Press.

Corcoran, P.B., Walker, K.E. and Wals, A.E.J. (2004), "Case studies, make-your-case studies, and case stories: a critique of case-study methodology in sustainability in higher education", Environmental Education Research, Vol. 10 No. 1, pp. 7-21.

Dilling, L., \& Lemos, M. C. (2011). Creating usable science: Opportunities and constraints for climate knowledge use and their implications for science policy. Global Environmental Change, 21(2), 680689. http://doi.org/10.1016/j.gloenvcha.2010.11.006

Doremus, H. (2003). A policy portfolio approach to biodiversity protection on private lands. Environmental Science \& Policy, 6(3), 217-232. http://doi.org/10.1016/S1462-9011(03)00036-4

Feiock, R. C., Tavares, A. F., \& Lubell, M. N. (2008). Policy Instrument Choices for Growth Management and Land Use Regulation. Policy Studies Journal, 36(3), 461-480. http://doi.org/10.1111/j.15410072.2008.00277.x

Freeman, R. C., Bell, K. P., Calhoun, A. J. K., \& Loftin, C. S. (2012). Incorporating Economic Models into Seasonal Pool Conservation Planning. Wetlands, 32(3), 509-520. http://doi.org/10.1007/s13157012-0284-x

Gerber, J.-D., \& Rissman, A. R. (2012). Land-conservation strategies: the dynamic relationship between acquisition and land-use planning. Environment and Planning A, 44(8), 1836-1855. http://doi.org/10.1068/a44395

Godemann, J. (2008). Knowledge integration: a key challenge for transdisciplinary cooperation. Environmental Education Research, 14(6), 625-641. http://doi.org/10.1080/13504620802469188

Golden, H. E., Creed, I. F., Ali, G., Basu, N. B., Neff, B. P., Rains, M. C., ... Lang, M. (2017). Integrating geographically isolated wetlands into land management decisions. Frontiers in Ecology and the Environment. http://doi.org/10.1002/fee.1504

Guston, D. H. (2001). Boundary Organizations in Environmental Policy and Science: An Introduction. Science, Technology \& Human Values, 26(4), 399-408. http://doi.org/10.1177/016224390102600401

Harris, F., \& Lyon, F. (2013). Transdisciplinary environmental research: Building trust across professional cultures. Environmental Science and Policy, 31, 109-119. http://doi.org/10.1016/j.envsci.2013.02.006

Hart, D. D., \& Calhoun, A. J. K. (2010). Rethinking the role of ecological research in the sustainable management of freshwater ecosystems. Freshwater Biology, 55, 258-269. http://doi.org/10.1111/j.1365-2427.2009.02370.x

Hockenstein, J. B., Stavins, R. N., \& Whitehead, B. W. (1997). Crafting the Next Generation of MarketBased Environmental Tools. Environment: Science and Policy for Sustainable Development, 39(4), 12-33. http://doi.org/10.1080/00139159709603637 
Hunter, M. L. (2005). A Mesofilter Conservation Strategy to Complement Fine and Coarse Filters. Conservation Biology, 19(4), 1025-1029. http://doi.org/10.1111/j.1523-1739.2005.00172.x

Irwin, E. G., Bell, K. P., \& Geoghegan, J. (2003). Modeling and managing urban growth at the rural-urban fringe: A parcel-level model of residential land use change. Agricultural and Resource Economics Review, 32(1), 83-102.

Jacobs, K., Lebel, L., Buizer, J., Addams, L., Matson, P., McCullough, E., ... Finan, T. (2016). Linking knowledge with action in the pursuit of sustainable water-resources management. Proceedings of the National Academy of Sciences of the United States of America, 113(17), 4591-4596. http://doi.org/10.1073/pnas.0813125107

Jansujwicz, J. S., Calhoun, A. J. K., \& Lilieholm, R. J. (2013). The Maine Vernal Pool Mapping and Assessment Program: Engaging Municipal Officials and Private Landowners in Community-Based Citizen Science. Environmental Management, 52(6), 1369-1385. http://doi.org/10.1007/s00267013-0168-8

Kirchhoff, C. J., Carmen Lemos, M., \& Dessai, S. (2013). Actionable Knowledge for Environmental Decision Making: Broadening the Usability of Climate Science. Annual Review of Environment and Resources, 38(1), 393-414. http://doi.org/10.1146/annurev-environ-022112-112828

Lang, D. J., Wiek, A., Bergmann, M., Stauffacher, M., Martens, P., Moll, P., ... Thomas, C. J. (2012). Transdisciplinary research in sustainability science: Practice, principles, and challenges. Sustainability Science, 7(SUPPL. 1), 25-43. http://doi.org/10.1007/s11625-011-0149-x

LeVert, M. (2008). Public Access to Maine's Private Lands: A Cultural and Economic Asset. Montana The Magazine Of Western History.

Levesque, V. R., Bell, K. P., \& Calhoun, A. J. K. (2017). Planning for Sustainability in Small Municipalities: The Influence of Interest Groups, Growth Patterns, and Institutional Characteristics. Journal of Planning Education and Research, 37(3). http://doi.org/10.1177/0739456X16655601

Levesque, V. R., Calhoun, A. J. K., Bell, K. P., \& Johnson, T. R. (2017). Turning Contention into Collaboration: Engaging Power, Trust, and Learning in Collaborative Networks. Society \& Natural Resources, 1920(May), 1-16. http://doi.org/10.1080/08941920.2016.1180726

Maiello, A., Battaglia, M., Daddi, T., \& Frey, M. (2011). Urban sustainability and knowledge: Theoretical heterogeneity and the need of a transdisciplinary framework. A tale of four towns. Futures, 43(10), 1164-1174. http://doi.org/10.1016/j.futures.2011.08.011

McCullough, E., \& Matson, P. (2012). Linking Knowledge with Action for Sustainable Development: A Case Study of Change and Effectiveness. In P. Matson (Ed.), Seeds of Sustainability (pp. 63-82). Washington D.C.: Island Press.

McGreavy, B., Calhoun, A. J. K., Jansujwicz, J., \& Levesque, V. R. (2016). Citizen science and natural resource governance: program design for vernal pool policy innovation. Ecology And Society, 21(2), 48.

McKee, A., Guimaraes, M. H., \& Pinto-Correia, T. (2015). Social capital accumulation and the role of the researcher: An example of a transdisciplinary visioning process for the future of agriculture in Europe. Environmental Science and Policy, 50, 88-99. http://doi.org/10.1016/j.envsci.2015.02.006

Miller, T. R. (2013). Constructing sustainability science: Emerging perspectives and research trajectories. Sustainability Science, 8(2), 279-293. http://doi.org/10.1007/s11625-012-0180-6

Miller, T. R., Wiek, A., Sarewitz, D., Robinson, J., Olsson, L., Kriebel, D., \& Loorbach, D. (2014). The future of sustainability science: A solutions-oriented research agenda. Sustainability Science, 9(2), 239- 
246. http://doi.org/10.1007/s11625-013-0224-6

Norton, D. A. (2000). Conservation Biology and Private Land: Shifting the Focus. Conservation Biology, 14(5), 1221-1223.

Paloniemi, R., \& Tikka, P. M. (2008). Ecological and social aspects of biodiversity conservation on private lands. Environmental Science \& Policy, 11(4), 336-346.

http://doi.org/10.1016/j.envsci.2007.11.001

Pirard, R. (2012). Market-based instruments for biodiversity and ecosystem services: A lexicon. Environmental Science \& Policy, 19-20, 59-68. http://doi.org/10.1016/j.envsci.2012.02.001

Polk, M. (2014). Achieving the promise of transdisciplinarity: a critical exploration of the relationship between transdisciplinary research and societal problem solving. Sustainability Science, 9(4), 439451. http://doi.org/10.1007/s11625-014-0247-7

Polk, M. (2015). Transdisciplinary co-production: Designing and testing a transdisciplinary research framework for societal problem solving. Futures, 65, 110-122.

http://doi.org/10.1016/j.futures.2014.11.001

Quinn, J. E., \& Wood, J. M. (2017). Application of a coupled human natural system framework to organize and frame challenges and opportunities for biodiversity conservation on private lands. Ecology and Society, 22(1), 39. http://doi.org/10.5751/ES-09132-220139

Schauppenlehner-Kloyber, E., \& Penker, M. (2015). Managing group processes in transdisciplinary future studies: How to facilitate social learning and capacity building for self-organised action towards sustainable urban development? Futures, 65, 57-71. http://doi.org/10.1016/j.futures.2014.08.012

Shogren, J. F. (Ed.). (2005). Species at Risk: Using economic incentives to shelter endangered species on private lands. Austin, TX: University of Texas Press.

Shortle, J. (2013). Economics and Environmental Markets: Lessons from Water-Quality Trading. Agricultural and Resource Economics Review, 42(1), 57-74.

Stokes, D. L., Hanson, M. F., Oaks, D. D., Straub, J. E., \& Ponio, A. V. (2009). Local Land-Use Planning to Conserve Biodiversity: Planners' Perspectives on What Works. Conservation Biology, 24(2), 450460. http://doi.org/10.1111/j.1523-1739.2009.01356.x

van Kerkhoff, L., \& Lebel, L. (2006). Linking Knowledge and Action for Sustainable Development. Annual Review of Environment and Resources, 31(1), 445-477. http://doi.org/10.1146/annurev.energy.31.102405.170850

van Kerkhoff, L., \& Lebel, L. (2015). Coproductive capacities: Rethinking science-governance relations in a diverse world. Ecology and Society, 20(1). http://doi.org/10.5751/ES-07188-200114

Wiek, A., Harlow, J., Melnick, R., van der Leeuw, S., Fukushi, K., Takeuchi, K., ... Kutter, R. (2015). Sustainability science in action: a review of the state of the field through case studies on disaster recovery, bioenergy, and precautionary purchasing. Sustainability Science, 10(1), 17-31. http://doi.org/10.1007/s11625-014-0261-9

Wiek, A., Ness, B., Schweizer-Ries, P., Brand, F. S., \& Farioli, F. (2012). From complex systems analysis to transformational change: A comparative appraisal of sustainability science projects. Sustainability Science, 7(SUPPL. 1), 5-24. http://doi.org/10.1007/s11625-011-0148-y

Wilcove, D. S., \& Lee, J. (2004). Using Economic and Regulatory Incentives to Restore Endangered Species: Lessons Learned from Three New Programs. Conservation Biology, 18(3), 639-645.

Wuelser, G., \& Pohl, C. (2016). How researchers frame scientific contributions to sustainable 
development: a typology based on grounded theory. Sustainability Science, 1-12. http://doi.org/10.1007/s11625-016-0363-7

Wyborn, C. A. (2015). Connecting knowledge with action through coproductive capacities: Adaptive governance and connectivity conservation. Ecology and Society, 20(1), 11. http://doi.org/10.5751/ES-06510-200111

Yin, R. K. (2009). Case study research: design and methods (Fourth). Thousand Oaks, CA: Sage Publications, Inc. http://doi.org/10.1097/FCH.0b013e31822dda9e

Zscheischler, J., \& Rogga, S. (2015). Transdisciplinarity in land use science - A review of concepts, empirical findings and current practices. Futures, 65, 28-44.

http://doi.org/10.1016/j.futures.2014.11.005 